My list of cases gives nothing to confirm or to deny this theory of Rosenbach. I can only call attention to the fact that left-sided cardiac dilatation seems to bear some relation to left-sided pleural effusion.

Signs of acute inflammation of the pleura were not found at autopsy in any of the Presbyterian Hospital cases, or in any of those analyzed in my former paper. Dr. Stengel did not find any such condition in the three autopsies held on the cases he reports. However, the fluid remored in Cases 1,2 and 3 had too high a specific gravity and too large an amount of albumin for a pure transudate. The fluid did not contain fibrin and was certainly not the result of an acute inflammatory process, but the phvsical characteristics of this fluid are such that it might have been the result of transudation com. bined with an exudate of a low-orade inflammation of the pleura, as has been surgosted by Rosenbach.

The pleura in Case 17 and in Case 4 of my previous paper were reported as thickened and whitened, although there were no signs of acute inflammation. It may well be that long-continued congestion had set up some subacute inflammation here, which was not active enough to cause fever. cough or pain. but may have aided materially in the production of the effusion.

Stengel suggests that a long-continued congestion produces some trophic change in the ressels of the pleura favoring the passage of the fluid and also calls attention to the fact that inflammation of the pleura may be latent and withont svmptoms. He suggests that in some crses an inflammatory element may be present in the production of these cardiac pleural effusions.

Gerhardt mentions a class of cases in which the effusion is very obstinate and recurs with great rapidity and persistence. Some of these cases have been tanned a great number of times, and the clinical picture they nresent is that of a chronic pleuritis of a low grade, combined with a process of transudation. due to the congestion of the vessels of the pleura.

Certain features of two of my cases suggest that some trophic change takes place in the pleura in cardiac disease that may render the pleura membrane a point of lessened resistance to infection.

Case 13 was an instance of acute pleurisy which occurred on the right side in a case of well-marked heart disease, with cardiac dilatation and symptoms of failing compensation. The pleurisy was accompanied by pain and fevèr.

In Case 12 the empyema developed in a case of double cardiac hydrothorax, greater on the left side, after both pleural sacs had been emptied by aspiration. The heart wa: much enlarged toward the left.

These two cases suggest that long-continued congestion may have altered the tissues of the pleura and that the pleural sac had become a locus minoris resistentiæ. Two isolated cases of this sort are not very convincing. but they are mentioned because they seemed to have some bearing on the question as to whether the effusion in cardiac disease is purely a transudate, or whether it is partly passive and partly inflammatory.

It seems probable, then, that the mechanism of the formation of fluid in these cases of pleural effusion in heart disease is not that of a simple transudate, but that congestion of the pleura produces a chronic inflammation of low grade, and that the effusion is both a transudate and an exudate. This is supported by the following facts: First, the specific gravity of the fluid and the amount of albumin contained in it is oten ton high to be consistent with the pure transudate: second. the effusion may precede, by a considerable length of time, cxternal edema or other serous effusions; third, the two cases reported suggest that the pleural sac particularly affected may undergo some trophic change, making it a point of lesser resistance to infection; fourth, the effusion in certain cases is very obstinate, lasts a long time and returns quickly after aspiration.

Gerhardt mentions the obstinacy and persistence of this effusion as a characteristic of this class of cases. Rosenbach, Brouardel and Liebermeister have called attention to this peculiarity of such pleural effusions.

Rosenbach mentions two cases in which the effusion lasted six and fourteen months respectively.

None of my cases showed this obstinacy of the effusion in any marked degree. Several of the patients were admitted to the hospital more than once for symptoms of fajling compensation and pleural effusion, but usually one or two tappings were sufficient to relieve the dyspnea, and the fluid returned slowly, even when the case was near to a fatal termination.

There was no case in the Presbyterian Hospital list in which the fluid persisted for any great length of time, and which was not relieved by one or, at most, two tappings. The effusion usually disappeared spontaneously as the patient grew stronger, or else increased slowly until death. Consequently, I can not sav that the Presbyterian Hospital list supports the statement of Gerhardt and Rosenbach, that great obstinacy is a characteristic of these pleural effusions in heart disease.

\section{PROLONGED DELIRIUM IN PERICARDITIS AND ENDOCARDITIS.}

WITH REPORT OF A CASE.*

EDGAR MOORE GREEN, A.M., M.D.

EASTON, PA.

I have taken the liberty of bringing to your notice the subject of delirium in certain diseases of the heart, not because it was possible for me to demonstrate any new scientific theory, but rather because from my reading and my own limited personal experience it seemed to me that prolonged delirium in such cases was quite unusual. It is, of course, well known that heart disease is a frequent complication of rheumatism, and endocarditis is much more common in such cases than is pericarditis. According to Whittaker, ${ }^{1}$ Bouillaud believed that in every case of acute articular rheumatism the heart was more or less affected. Williams states that 75 are affected in every 100 cases. Leudet fixes the ratio at 22 in 100 ; Sibson 20 in 100 . Wünderlich 19 in 100. Duchek 16 in 100 . Bamberger has claimed that 30 per cent. of cases of cardiac trouble arise from rheumatism, and Thompson has placed the figures at 16 and 20 per cent. On the other hand, Latham states that pericarditis only occurs seven times in 136 cases of rheumatism. The latter disease is certainly more apt to occur in severe cases, and is said to be more frequent when the inflammation has a tendencr to wander from one joint to another in rapid succession. It is said to occur very infrequently in cases of subacute or chronic rheumatism; in fact, some authorities denv that it ever occurs as a complication of the latter.

Ordinary cases of the disease run a comparatively

- Read at the Fifty-fifth Annual Session of the American Medical Association, in the Section on Practice of Medicine, and approved for publication by the Executive Committee: Drs. J. M. Anders, Frank Jones and W. S. Thayer.

1. Twentieth Century Practice. 
short course, frequently not more than eight or ten days, except where the amount of effusion is great, and these terminate in from three to six weeks. It will not be necessary for me to enumerate the ordinary symptoms and complications of this disease. I may say, however, that the rarer symptoms mentioned by most authorities are aphonia and hoarseness, from pressure on the left recurrent or laryngeal nerve, syncope from anemia of the brain resulting from pressure on the large vessels of the heart or myocarditis, vomiting from pressure on the phrenic nerve. Stupor, delirium and coma are mentioned as occurring from hyperemia due to pressure on the vena cava or to the accumulation of toxins in the blood. All authorities whom I have consulted, however, have stated that the latter signs usually show themselves in the last stages of the disease. Austin Flint has reported cases marked by delirium, but in all the cases of which I have read the delirium has been of comparatively short duration.

It will not be necessary for me to give a detailed report of the symptoms of this case, but a résumé may be given as follows:

History.-Dec. 15, 1902, I was called to risit a man, age. 46 , whom I found to be suffering from acuie rheumatism. His previous health had been good. Early in life he was said to have had an attack of brain fever, but of this I could obtain no detailed nistory. He had had two attacks of acute rheum. atism, each lasting several weeks. In one of these attacks he had been under my care, and, although the case was somewhat tedious, there were no complications and he made an uninterrupted recovery. There was no specific history. During the first week of his illness the inflammation was rather migratory in character, at one time an arm would be affected, on another day one knee would be inflamed, or one ankle or possibly both ankles, at another time an elbow or wrist. During this time the temperature ran as high as 103 to 104 degrees. At the end of about one week he was suddenly taken with pain in the left side about the level of the fifth and sixth libs. This pain was acute in character and accompanied each inspiration, the respiration became more rapid, running up to 37 or 38 per minute, pulse 100 to 108 , temperature 100 to 101 degrees.

Examination.-Auscultation at this time revealed symptoms of acute pleurisy, and also a systolic murmur over the precordium, but more intense at the apex. There was also found a to-and-fro friction sound at the fourth and fifth interspaces directly over the heart. The sounds of the heart rapidly diminished in force and loudness. Visible impulse of the heart was practically obliterated. Percussion of the chest revealed great increase in the lateral diameter of the cardiac dullness. The urine was about normal in quantity. but was quite high colored and of high specific gravity. There was no albumin nor -ugar, but urates were present in considerable excess.

symptoms.-In addition to great pain in the region of the heart there was difficulty in swallowing. The latter symp:om was sn marked that even the swallowing of liquids caused sreat discomfort and frequently he was unable to take more than one or two swallows in succession. At the same time lie became extremely restless, talkative and frequently saw imaginary objects. It was exceedingly difficult to induce leep. Morphin, $1 / 4 \mathrm{gr}$, with atropin would partially relieve nain. but seldom caused more than one hour's continuous -lcep. He was exceedingly restless, frequently trying to get out of bed and almost constantly trying to pick up imaginary objects. His most frequent delusion was that he was travel. ing in some distant city or foreign country, although he usually recognized those about him. After a number of days he heliever he was on a sort of houseboat on a trip which his wife was conducting. His usual question when I visited him in the morning would be. "Well, how did you get here tolay?:" It is difficult to understand how this delusion could have originated. His occupation for several years had been that of superintendent at large iron works and during certain seasons of the year he was in the labit of traveling for the making of purchases in various parts of the West. At no time did his delirium become violent, though, as stated before, he frequently attempted to get out of bed. This mental condition continued without interruption until January 26 , or about five weeks, when, after a fair night's sleep, the nurse stated that his mind wandered but little. After this time the mind was more or less confused for a few moments at a time each day for two weeks, but it may be said that the mental condition steadily improved. From the time of the onset of pericarditis his temperature did not run above 100.4 degrees. As a rule, it would fall to 99 or even 98.6 degrees in the morning and would rise to 100.2 degrees in the evening.

Dyspnea was always present, though it did not develop to the extent of orthopnea. Cyanosis was also present and its presence, of course, indicated the extent to which the brain must have been disturbed by this venous congestion. Osler states in his practice that delirium and marked cerebral symptoms are associated with the hyperpyrexia of rheumatic cases. I think, however, that you will agree with me that the degree of fever was not sufficient in this case to account for the continuance of delirium through so long a period of time.

Treatment.-December 31, Dr. William L. Estes of South Bethlehen was called to see the case in consultation. The treatment adopted at this time was large doses of citrate of lithium and potassium with iodid of potassium three times a day. Tineture of strophanthus was also given three times a day in doses of ten drops. Fortunately for the patient the bowels were rather active, frequently four to five stools per day, and these were often more or less watery in character. Under the action of the alkaline salts given with copious draughts of water, the kidneys became more active, the quantity of urine running some days as high as 102 ounces and not on any day being allowed to fall below normal. The skin was kept active and perspiration continued profuse. Is soon as the patient's condition permitted general massage was giren in order to tone up the general system.

Result.-Recovery, of course, was very slow, and he was not allowed to take up any work until March 31 ; even then the amount of physical exercise was much restricted. In October, however, he started West on a business trip and much of his time was spent at great elevations above the sea level and yet with no untoward result. On November 8 he left Durango, Colorado (elevation 6,520 feet), at 8 a. $m$. and went to Silverton (elevation 9,224 feet), where he walked two miles to a stamping mill and there climbed up to a height of 150 or 200 feet, afterward returning by train to Eureka. The following dlay he drove twenty-six miles alone, starting from Silverton (elevation 9,224 feet), and going to Ouray ( 7,700 feet), passing meanwhile over a height of 11,002 feet, then on nine miles further to Mount Sneffles (elevation between 11,000 and 12,000 feet), and back to Ouray at $6 \mathrm{p}$. m.

The ability to take such an amount of exercise at such an elevation would seem to me to show how thorough his recovery had been; moreover, careful physical examination of the chest made within the last fow davs rerealed no markedly unnatural sounds. The cardiac impulse is normal in location and force. and the sounds almost natural in character, except for a slight blowing murmur heard at the apex.

How They Do It in Iowa.-A Red Oak paper of August 20 has the following: "Dr. A. A. Potter, who advertised that he would be in Red Oak last Saturday and meet all who wished to have their ills taken away and their youth renewed, was on time all right. But he met with grief a plenty. He had no more than unpacked his pill box when a local officer arrested him and took him before Mayor Reiley to answer to the charge of practicing medicine in Red Oak without having procured a license. The doctor plead guilty and was fined $\$ 29.10$. He left town."-Ionca Health Bulletin. 